Canadian Journal of Higher Education Revue canadienne d'enseignement supérieur

Volume 47, No. 2, 2017, pages 22 - 46

\title{
Culturally Responsive Pedagogy: Indigenizing Curriculum
}

Karen Ragoonaden

The University of British Columbia Okanagan Campus

Lyle Mueller

\begin{abstract}
This article examines the impact of culturally responsive pedagogy in an introduction to university course developed in collaboration with local and place-based First Nations communities, Aboriginal Access Studies and the Faculty of Education of the University of British Columbia's Okanagan Campus. In keeping with requests that Indigenous worldviews be incorporated into curriculum, the content of EDUC 104, modelled on the University of South Carolina's University 101 Programs, was adapted to incorporate Indigenous traditions of teaching and learning. The introductory course included a holistic approach aimed at supporting the social and emotional well-being of students. Facilitated by peer mentoring, collaborative circles of learning introduced seminal concepts and facilitated the progressive use of newly learned skills. As part of a longitudinal research, the following presents the content of interviews conducted at the conclusion of the courses. Analysis indicated that three themes emerged emphasizing the importance of the circles of learning, peer mentoring, and the relationship with the instructor. In particular, the results demonstrated the perceived value of the course from the students' perspectives.
\end{abstract}

\section{Résumé}

Cette recherche souligne l'effet d'une pédagogie culturellement adaptée en contexte d'un cours universitaire de première année. La conception et l'élaboration du cours ont été informées par une collaboration entre les communautés autochtones environnantes, Aboriginal Programs and Services et la Faculté d'éducation de la University of British Columbia, Okanagan 
campus. Par opposition aux discours magistraux, des cercles d'apprentissage ont appuyé l'enseignement de nouveaux concepts et ont facilité l'utilisation progressive des compétences nouvellement acquises. Dans le cadre d'une recherche longitudinale, trois thèmes identifiant l'importance des cercles d'apprentissage, le mentorat par paire et le rapport entre étudiant-professeur ont été identifiés. L'article présente également le contenu d'entrevues effectuées à la fin des cours.

In keeping with requests that worldviews of First Nation, Métis, and Inuit Peoples (FNIM) of Canada be incorporated into content steeped in Eurocentric, linear educational progression, this study aims to examine how a fusion of Indigenous knowledges and nonIndigenous traditions of learning impact the academic development of Aboriginal Access Studies students. Culturally responsive pedagogy (CRP) is situated in a framework that recognizes the rich and varied cultural wealth, knowledge, and skills of diverse learners. This approach seeks to develop a philosophical view of teaching that is dedicated to nurturing students' academic, social, emotional, cultural, psychological, and physiological well-being (Anuik \& Gillies, 2012; Battiste \& Henderson, 2009; Cherubini, 2014; Gay, 2000; LadsonBillings, 1994;). Appreciating the need to conceptualize and develop culturally responsive pedagogy, this paper presents the results of a two-year longitudinal study focused on determining the perceived short-term value of the course from the students' perspectives.

Regarding the seminal concepts of respect, relevance, reciprocity, and responsibility, we recognize the traditions and customs of the Syilx Okanagan Nation in whose unceded territory the University of British Columbia's (UBC) Okanagan campus is situated. In September 2005, the Okanagan Nation Alliance welcomed UBC to traditional Syilx territory in an official ceremony, Knaqs npi'lsmist, where a Memorandum of Understanding was signed. Accordingly, both authors acknowledge settler (Karen) and Métis (Lyle) perspectives during on-going and continuous collaborations with colleagues from Aboriginal Programs and Services (APS), and community members from Westbank First Nation, Ki-low-Na Friendship Society and the Métis Society of British Columbia. In an attempt to counteract the prevalence of pan-Indigenous approaches to pedagogy, Anuik \& Gillies (2012) refer to the term Aboriginal as First Nation, Inuit and Métis Peoples of Canada. Recently, the Social Sciences and Humanities Research Council (SSHRC, 2016) proposed that the term Aboriginal fails to reflect the historical, cultural and linguistic diversity among First Nations, Inuit and Métis Peoples. SSHRC defines the term Indigenous Knowledge as the "traditional knowledge is specific to place, usually transmitted orally, and rooted in the experience of multiple generations. It is determined by an Aboriginal community's land, environment, region, culture and language. Traditional knowledge is usually described by Aboriginal peoples as holistic, involving body, mind, feelings and spirit" (http://www.pre.ethics.gc.ca/eng/policy-politique/initiatives/tcps2-eptc2/chapter9-chapitre9/). Anuik and Gillies (2012) refer to Indigenous Knowledge as the foundational and practical knowledge held by Indigenous peoples globally. In this article, usage of the term Aboriginal is dependent on institutional or policy-related convention.

Conceived as an opportunity for students to transition to higher education, UBC Okanagan's Aboriginal Programs and Services offers access studies to FNIM students who have not met the requirements for admission into first-year university courses. This program prepares students for degree studies by providing parameters to facilitate a holistic ap- 
proach to the social, emotional, and cultural adaptation to campus life and to first-year university level courses. In this program, FNIM students enrol in developmental classes in biology, education, English and math, earning university credits in each course. The curriculum of each of these developmental classes was Indigenized by one of the authors of this paper, Lyle Mueller, former Special Advisor, Aboriginal Affairs to the Provost's Office. After completing the Aboriginal Access program with a minimum of $60 \%$, students can choose to enrol in first-year courses. This paper discusses the impact of the fourth and last course, EDUC 104 Introduction to Academic Pedagogy: An Aboriginal Perspective.

Informed by the work of Archibald, Pidgeon, and Hawkey (2009) and emphasizing Kirkness and Barnhardt's (1991) 4Rs, (respect for First Nations' cultural integrity, relevance to First Nations perspectives and experiences, reciprocal relationships, and responsibility through participation), a secondary objective of this study was to examine how postsecondary institutions respond to their roles and responsibilities in the area of higher education aimed at Indigenous students. Having a better understanding of how educators can support the academic successes of all first year students is an emergent and important priority in Canadian educational contexts (Canadian Council on Learning; 2009; Canadian Council on Social Development, 2012).

\section{Success in First-Year University Courses}

The first year at university is a critical period during which students' attitudes, identities, goals, and future successes in higher education are most influenced (Ender \& Newton, 2000; Kuh, 2001; National Resource Center, 2002; Upcraft and Gardner,1989). In Canada, many institutions have made significant commitments to retention measures that include programs similar to the University of South Carolina's (USC) University 101 (McGuigan, 2005) Programs. North America's leading thinker on retention, Tinto (1993; 2002), proposes that programming directly focused on supporting students in their first year at university is vital to the retention of students. Pidgeon (2009) adds an Indigenous perspective to the discussion on retention by emphasizing the 4 Rs and Indigenous cultural integrity. In keeping with conclusive research in this area, she refers to a lack of preparation in the $\mathrm{K}-12$ sector and lack of culturally responsive programs and support services provided by higher education institutions, as well as the continuing prevalence of systemic acts of discrimination and racism in the classroom and in institutional policies as detriments to the retention rates of First Nations, Inuit and Métis Peoples of Canada in postsecondary contexts (Archibald, Pidgeon, \& Hawkey, 2009; Battiste, 2002; Cherubini, 2014; Kuokkanen, 2007; Marker, 2004; Pidgeon, 2008).

USC's hallmark course, University 101 Programs, is an international model for firstyear seminars that introduce students to campus life (Barefoot, 1993; Gardner, 1980; 1981). Launched in 1972, University 101 is a three credit, letter-graded course for firstyear and transfer (access) students. The purpose of University 101 is to help new students make a successful transition to academic studies, on intellectual, social and emotional levels. The course aims to foster a sense of belonging, promote engagement in the curricular and co-curricular life of the university, articulate the university's expectations of the students and faculty, support students' development and application of critical thinking skills, and help students clarify their purpose, meaning, and direction. The highest quality first-year experiences place a strong emphasis on critical inquiry, frequent writing, infor- 
mation literacy, collaborative learning, and other skills that develop students' intellectual and practical competencies (National Resource Center, 2002; National Survey of Student Engagement, n.d; Padgett \& Keup, 2011).

For first year students, the adaptation and response to university life can be complex and challenging. Higher education institutions recognize the importance of facilitating first-year students' successful integration in the social, emotional, and academic communities of campus life. These types of supports are considered important factors in long-term retention and degree completion (Cuseo, 2002; 2003; Tinto, 1993; 2002). Recognizing the challenges and complexities of adaptation to first-year university studies, an educational perspective based on CRP can provide the necessary parameters to ensure success for novice students.

\section{Culturally Responsive Pedagogy}

CRP is an approach that focuses classroom curricula and practice on students' cultural frames of reference (Gay 2000; 2010; 2013; Ladson-Billings, 1994). It is a pedagogy that recognizes students' differences, validates students' cultures, and asserts that cultural congruence of classroom practices increase students success in schools. In conventional Western school structure, Eurocentric practices focusing on individual disciplines where students are required to learn in a linear fashion abound, to the detriment of those hidden, othered voices (Armstrong, 2005; Claypool \& Preston, 2011; Preston \& Claypool, 2013). In keeping with this, research indicates that students who are culturally diverse have a tenuous relationship with schools whose educational practices emphasize traditional, Eurocentric, and normative approaches (Battiste, 2002; 2013; Claypool \& Preston, 2011; Sharpe \& Arsenault, 2009). These types of practices tend to exclude learners from non-mainstream cultural backgrounds by ignoring their distinctive cultural habitus and cultural capital. This obfuscation culminates in a devaluation of identity and way of being, resulting in cultural discontinuity for learners and the educational institution in which they are enrolled (Egbo, 2005; 2009; 2011; Ogbu, 1982; Parhar \& Sensoy, 2011).

Ogbu (1982) addresses the negative educational impact of normative educational discourses on minorities by conceptualizing the term cultural discontinuity. This renowned Nigerian-American anthropologist makes the distinction between involuntary and voluntary minorities. Voluntary minorities (e.g., immigrants) tend to form non-oppositional secondary differences with the dominant culture while, involuntary minorities (e.g., Native American) tend to form oppositional secondary differences with the dominant culture. At issue is the fact that both voluntary and involuntary minorities are required to adhere to dominant (White) American cultural frames of reference if they want to acquire upward social and economic mobility (Ogbu, 1978). Consequently, the concept of cultural discontinuity, which hypothesizes that major differences in the school experiences of learners lie in the incongruence of their cultural background and the culture of the school, engages in the difficult discussion about the implementation of CRP in higher education.

Studies in diversity education also indicate that normative stances regarding the scholarship of teaching and learning, despite best efforts, reinforce race, class, and gender inequities (Ball \& Tyson, 2011; Gay 2010; 2013). Positive educational outcomes for students, particularly those from non-mainstream backgrounds, depend on the degree of a postsecondary institution's commitment to develop inclusive practices that embrace 
and value difference (Egbo, 2005, 2009; Gay, 2000; Ladson-Billings, 1994). Emerging as a global trend, pluralistic societies can position educational institutions to provide opportunities to access social and cultural capital, a necessary condition for developing socioeconomic mobility. By recognizing that public institutions covet the reproduction of the economic, political, social, and cultural mores of a Eurocentric worldview, CRP intuitively responds to the "hidden" voices by validating multiple understandings and ways of being (Ball \& Tyson, 2011). Grant and Gibson (2011) reviewed studies that demonstrate how curricular choices relating to class, race, and gender impacted on the development of worldviews, values, and educational practices. These differences were representative of distinctive socio-economic and cultural demarcations that either ensured or negated life chances of underrepresented populations. These demarcations or codes are intrinsic beliefs, traditions, and behaviours found in textbooks, practice, and policy that validate and reproduce mainstream ideology. When normalized, this reinforcement of dominant group values in social institutions such as schools and universities are recognized as a necessity for success in society (Delpit, 2006). These studies concluded that the best predictors of success in education are life experiences, attitudes, disposition toward difference, and a commitment at individual and institutional levels to embody democratic and inclusive pedagogical practice such as CRP. Within the North American educational context, there is a progressive movement to adapt traditional curricula to the representative realities of critical pedagogy, critical multiculturalism, and CRP (Nieto, 2000; 2004; Ragoonaden, Cherkowski, Baptiste \& Desprès, 2009; Villegas \& Lucas, 2002; Shariff, 2008). Curricula can be better positioned to reflect diverse ways of teaching by bridging the gap between demographics, experiences, and cultural values (Ball, 2009).

\section{Indigenizing Curriculum Using CRP}

As indicated University 101, developed by USC, has provided opportunities for 30 years of research by the National Resource Center. This centre is a recognized national and international academic model whose mandate is to introduce freshmen students to first-year university studies. In the same vein, EDUC 104 Introduction to Academic Pedagogy: An Aboriginal Perspective, was developed according to the founding principles of University 101 and has been infused with the First Peoples Principles of Learning (FNESC, 2008). EDUC 104 aims to facilitate transition to university and improve the first-year experience of Indigenous students. Using the framework of CRP, this course attempts to redress the cultural discontinuities between contemporary education and the emergent diversity in school populations at postsecondary institutions.

Infused with the holistic perspective of Indigenous epistemology, an ancillary objective of the course has been to "end the fragmentation Eurocentric educational systems imposed on First Nations students and facilitate the goal of wholeness to which Indigenous knowledge aspires" (Battiste, 2002, p. 30). In collaboration with UBC Okanagan's Aboriginal Programs and Services as well as local and place-based community partners, Ki-Low-Na Friendship Society, Westbank First Nation and Métis Society of British Columbia, CRP has been conceptualized to reflect interconnectivity in a nested system, where all facets of learning link with each other on emotional, social, mental, and physical levels. Teaching from this holistic perspective offers a very different outlook from conventional Western school structure, where individuality and competition are the norm (Armstrong, 2005; Battiste, Bell, \& Findlay, 2002; Claypool \& Preston, 2011; Preston \& Claypool, 2013). 


\section{Medicine Wheel of Learning}

One variant of the Medicine Wheel of Learning described in The Sacred Tree: Reflections on Native American Spirituality (Bopp, Bopp, Brown, \& Lane, 2004) served as an important articulation in the conceptualization and development of CRP. It is of note that the Medicine Wheel of Learning is not common to all First Nations. In keeping with the cultural and linguistic diversity of the First Nations People of Canada, many variations of the Medicine Wheel exist. However, the common element found in most Indigenous nations is the concept of (w)holism ${ }^{1}$ (Archibald, 1995). Similar to Archibald et al.'s (2009) Wholistic Indigenous Framework, the Medicine Wheel of Learning provides a holistic approach to education embedded in a philosophy and pedagogy that seeks to nurture the four dimensions of the learner. The underlying principle of the Medicine Wheel emphasizes interdependence and unity as an integral educational experience emphasizing the four facets of the self as described in The Sacred Tree (Bopp, Bopp, Brown, \& Lane, 2004).

Recognizing that First Nations People differ significantly in terms of history, language and cultural practices, there are significant critiques describing misappropriation of the Medicine Wheel. Often, the Medicine Wheel is used out of context to place and is improperly applied to the First Nations to which it relates. For example, Okanagan traditional knowledge and stories are framed on the Four Food Chiefs, a Syilx (Okanagan) oral story based on the Skemxist (Black Bear), Siya? (Saskatoon Berry), Speetlum (Bitteroot), and Ntityix (Spring Salmon) (Armstrong, 2000; 2005; Cohen, 2010). Recognizing the diversity of Indigenous students attending UBC's Okanagan campus, the authors, in consultation with APS colleagues and First Nations community members, explored how the Medicine Wheel presents a worldview that embraces concepts of cyclical interdependency and equilibrium in a holistic, interconnected and nested system. A Medicine Wheel is a circle divided into four parts, represents a wide variety of teaching practices emphasizing the centrality of a balanced position, and focuses on the individual's volition to engage in experience (Bopp et al., 2004; FNESC, 2008).

By applying precepts of the Medicine Wheel as described in The Sacred Tree (Bopp et al., 2004) to the cycle of learning, this developmental course, was intended to provide an opportunity for Aboriginal Access students to gain the academic skills necessary for admission to first-year university courses in a culturally responsive manner. The teachings summarized in the book The Sacred Tree represent ethical concepts and teachings of North American First Nations societies concerning the nature and possibilities of human existence. Composed of twelve teachings that focus on wholeness, change, and selfvolition, Bopp et al., (2004) identify four dimensions of learning. These four aspects of every person's nature are reflected in the four cardinal points of the Medicine Wheel. The self, situated in the nexus of the circle, is central to the development of the four aspects of one's being. Within this context, in order to learn in a whole and balanced manner, all four dimensions of an individual have to be actively engaged and committed in the educational process. These four dimensions are wisdom and logic (mental), illumination and enlightenment (spiritual), trust and innocence (emotional), and introspection and insight (physical).

As noted in The Sacred Tree (Bopp et al., 2004), there are numerous variations of the Medicine Wheel of Learning. Within the diverse representations of the Medicine Wheel, the various learning styles and types of intelligence are valued equally. This is similar 
to other educational approaches that recognize individual learning styles, modify teaching and learning practices accordingly, and create different paradigms for teaching and learning. For example, the first author's previous work focused on integral education, a conceptual framework that examined how educational behaviours, educational cultures, educational experiences, and educational systems impacted on teaching and learning in primary education (Ragoonaden, Cherkowski, \& Berg, 2012). As indicated earlier, Archibald et al., (2009) conceptualized the Wholistic Indigenous Framework, which emphasizes the interconnectedness of the intellectual, physical, emotional, and spiritual elements of human development. Important consideration is given to the connections and relations of family and community as well as the impact of institutional and political influences on the individual's well-being.

\section{Creating Educational Space}

Acknowledging the importance of the physical environment in Indigenous epistemology, the course, Introduction to Academic Pedagogy, was offered in a novel teaching and learning space, the Innovative Learning Centre (http://blogs.ubc.ca/centre/) in the Faculty of Education. Housed in a regular classroom, rows of desks were replaced with standup tables, stability stools, and height-adapted chairs, which were all integral components of the design. Along one side of the classroom, comfortable sofas and chairs, positioned in front of bright, airy windows, lined with plants provided a space for students to engage in small-group collaborations. Writing walls, access to iPads, and computers on high tables allowed students to sit or stand and use diverse mediums to write on/in and to do research. Recognizing the diversity of learning styles, this educational space gave students the option to choose the physical and technological parameters of their learning environment.

In keeping with the Medicine Wheel's focus on wisdom and logic, the course content of South Carolina's University 101 course was adapted to incorporate approaches found in the The Sacred Tree (Bopp et al., 2004). Ellis, Toft, and Dawson's (2012) seminal text Becoming a Master Student provided the necessary parameters to teach the developmental skills in a centric, holistic manner. Developmental skills were identified using the table of contents of this well-established textbook. Interestingly, each of the learning objectives of the textbook chapters was positioned within an interconnected circle, drawing parallels with the self, society, and education. However, unlike the textbook, linear progressive stances were not used to teach developmental skills relating to reading, writing, and oral communications. In keeping with the learning outcomes of the Master Student textbook, experiential strategies relating to learning styles, time management, note-taking, critical reading and thinking, oral communications, health management, and financial literacy were introduced by the instructor, then experimented with in the circles of learning.

Acknowledging the circular nature of the Medicine Wheel, enrolment in this course was limited to 24 students. Each month during the 13-week semester, students were organized into a different learning circle made up of four participants. In keeping with the positioning of the self in the Medicine Wheel's centre, each individual was made aware of his or her responsibility in the learning process. As they rotated through the semester, first-year students got a chance to meet and learn with a new cohort on a monthly basis. Since new developmental skills were introduced weekly via the learning circles, participants were encouraged to talk about and deconstruct the concepts and to renegotiate 
their understandings of the skill being developed. Then, through experiential activities, participants in each of the circles of learning applied the concepts to readings and other didactic materials to their own individual program of study.

In the Aboriginal Access Program, which is a transition program, students were on campus full time, taking mandatory developmental courses in English, biology and math. In keeping with the interconnectedness of Indigenous pedagogy, emphasis was placed on the interrelationship of the new knowledge to various contexts. Acknowledging the importance of illumination and enlightenment embedded in the various representations of the Medicine Wheel, the regular presence of Elders, guest speakers from local and placebased First Nations communities and active peer mentoring from upper-level Indigenous students were integral components of this highly supportive educational environment. By understanding the physical, social, and emotional needs of first-year students, Aboriginal Programs and Services provided regular workshops, lunch gatherings, as well as socio-cultural events, such as participation in sweat lodges and salmon feasts, to first-year students as well as upper-year students. Encouraging criticality and intellectual debate, transmission-style teaching by virtue of lectures and PowerPoint presentations were kept to a minimum. For example, in order to establish parameters for the learning environment, at the beginning of each class, the instructor would formally introduce new concepts in the developmental continuum within the scope of 20-minute lectures and/or interactive discussions. Then, a series of experiential activities, which often included a guest speaker, would take up the remainder of the class time.

Despite the fact that positive results have been reported regarding the three-credit University 101 course (Barefoot, 1993; 2000; Barefoot et al., 2001; Cuseo, 2002, 2003; Tinto, 2002), few studies have attempted to delve deeper into understanding the impact and value of the course using a qualitative approach. Most studies have been quantitative, comparing course participants with non-participants according to a measured variable such as retention, graduation, academic success, and integration to university life. To date, little research exists on first-year credited introduction to university courses that take a qualitative methodological approach toward understanding the perceived value of the course, particularly from the students' point of view. Given that little qualitative research has been done to study students' perceived values of the course, the current study seeks to fill this apparent gap in the research.

\section{Methods}

This longitudinal, mixed-methods study began in December 2013 and concluded in December 2015. It adhered to research mandates established by the university's ethics committee as well as acknowledgement and support from Aboriginal Programs and Services. In order to ensure the objectivity of each participant's response, a research assistant introduced the study, underscored the confidential nature of the work, reiterated the withdrawal policy, asked for informed consent, conducted the interview, and collected the initial data. The first author, also the course instructor, did not have access to the data till the last day of grade appeal as dictated by university-wide policy. Once ethical permission was granted, seventeen out of a combined sixty-four students enrolled in 2013, 2014, and 2015 agreed to sit for a semi-structured interview. Data inquiring into the impact of the skills acquisition and the ensuing application in other courses was collected. Demograph- 
ic information indicated that eleven women and six men between the ages of 18 and 56 participated in the research. All Aboriginal Access students self-identified as First Nation or Métis. They were not required to provide any geographic data relating to the location of their homes and/or appartenance to a First Nation.

Based on the grounded theory approach (Glaser, 1992; Glaser \& Strauss, 1967), the semi-structured interviews provided the data from which new information was generated. The 10 question interviews were divided into three sections. Questions 1-3 inquired into the type of skills acquired and how these are applied to other courses. Questions 4-6 examined how and if the course content was beneficial to the student's overall university experiences. The last series of questions interrogated the benefits of a culturally responsive course as well as the impact of the peer mentors in the students' learning environment. During the interview, participants also responded to a five-point Likert scale relating to the acquisition of specific academic skills as dictated by the table of contents of the textbook (question 2). Data collected from the Likert scale in the questionnaire was tabulated and considered during analysis.

Transcription of interviews and thematic coding of the responses resulted in the emergence of identifiable themes in the participants' responses. Measures taken to determine thematic codes included using the constant comparative method to identify and to analyze the data collected from the interviews. Themes and patterns were identified, organized, and analyzed.

To begin with, the initial coding was conducted within the first set of data coming from the student interviews. Through initial coding, in vivo codes (verbatim quotes from data) and/or important words or groups of words were identified: circles of learning, socialization, community, peer mentors, academic support, teacher. Once in vivo codes were identified, the constant comparative method was applied again to all interviews and the following categories emerged:

Theme 1: Circles of learning based in CRP created social relationships and community;

Theme 2: Peer mentoring provided socio-emotional and academic support through shared narrative; and

Theme 3: The importance of the student-teacher relationship.

\section{Results}

In the following section, Figures 1 and 2 provide an overview of the data relating to specific (as indicated in the textbook by Ellis et al., 2012) and generalized perceived skill development (an overall perspective of the skill development) of participants. To support the selfreported data, the thematic analysis of student interviews will be presented, then discussed.

\section{Skill Development}

Figure 1 represents the results tabulated from question 2 in which a five-point Likert scale was used to determine the students' perceived development of specific academic skills as identified in the Ellis et al. (2012) textbook. In keeping with the content of the textbook, each chapter reflected the skill being taught. 


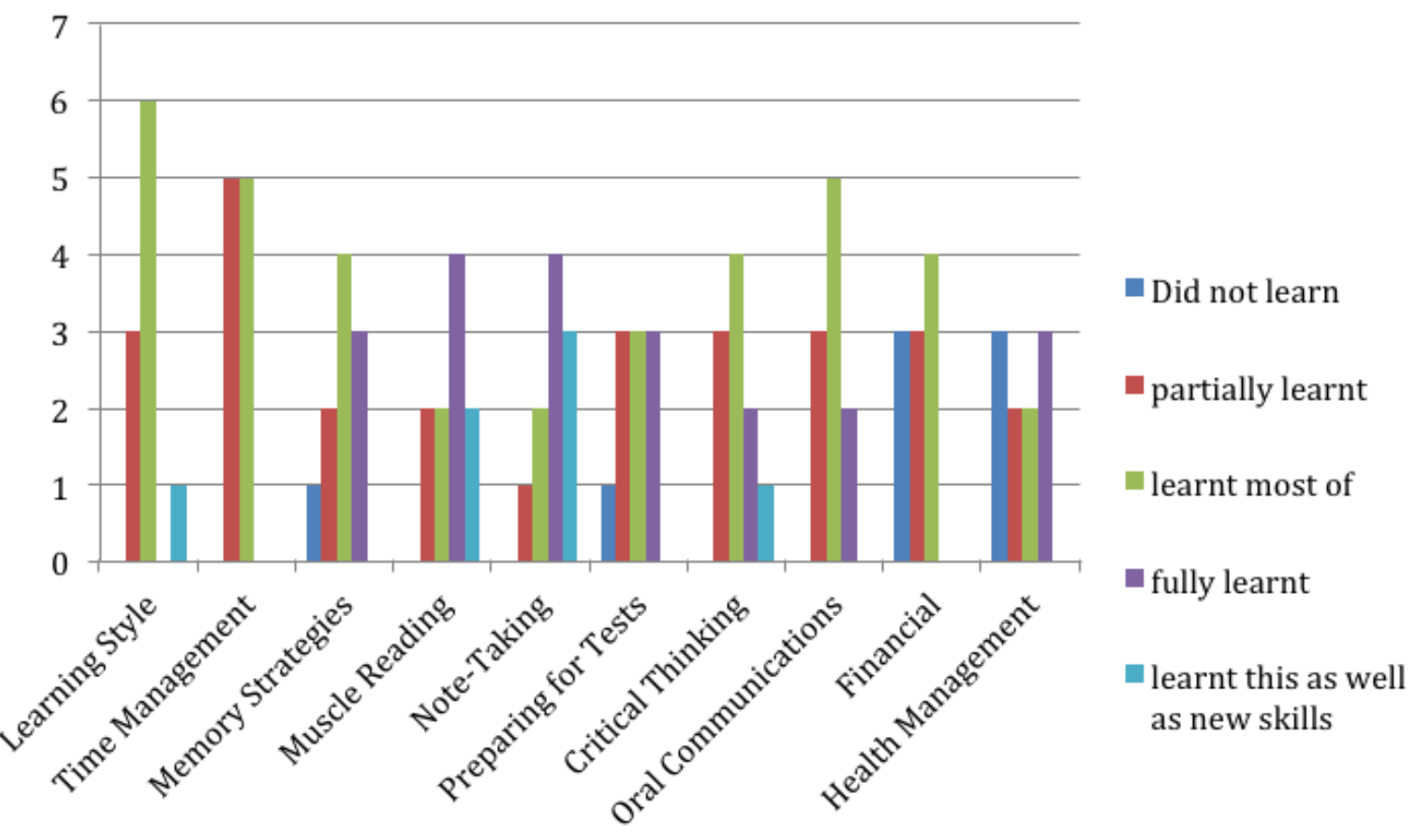

Figure 1. Specific Skill Development

Results emanating from Figure 1 indicated that the skills relating to muscle reading and note-taking had the highest response in the category of fully learnt. Participants learned most of the skills relating to their learning style, time management, memory strategies, critical thinking, oral communications and financial management. Areas that required more development included memory, preparing for tests, and health management.

Question 6 in the interview specifically asked students about the perceived values relating to the acquisition of the generalized academic skills necessary for university admission. Figure 2 demonstrates that the majority of students indicated the skills learned met expectations and in some cases exceeded expectations.

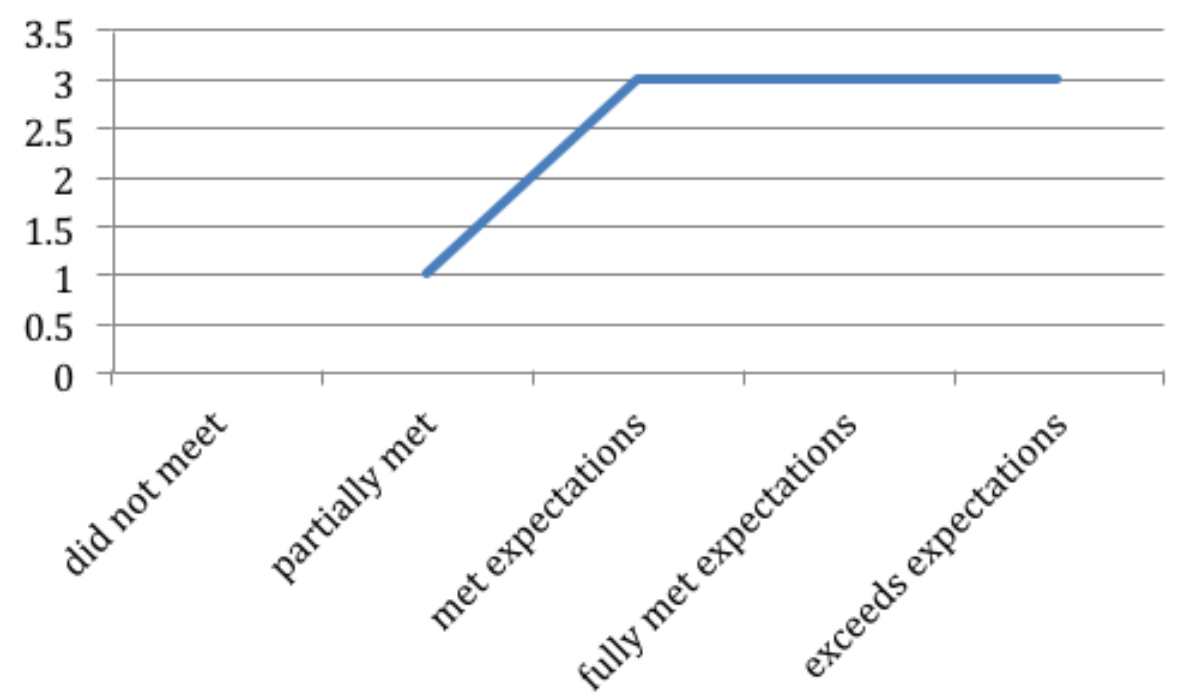
Academic Skill Development

Figure 2. Generalized Skill Development 
The above data was supported by comments made during the interview about the impact of this course on students' skill development. Please note that all transcriptions are verbatim.

It was a great transition course. It was ... I've been out of school for a year, so it was a great class to get back into reading, get back into all the different steps, and also learn about what it takes to get to that next level of thinking and become successful at university. (2013A1)

It was a helpful course. It's been quite impactful. (2014B3)

I like the amount of hands-on [in] a smaller class, (2015C4)

Not really like your average class, where it's just talking about things that happened ten10, twenty 20 years ago. It's more recent, . [I learned] Cornell notetaking system, effective listening, . . . ....and different ways of studying., I guess I learned a lot. More than I thought., I already have [recommended it to someone for next year]. (2013A3)

\section{Emergent Themes in CRP}

As indicated, as the interviews were transcribed, coded, and analyzed, three themes emerged.

Theme 1: Circles of learning based on CRP created social relationships and community. Responses from the interviews indicated that the circles of learning provided students with the necessary parameters to foster the development of a sense of community.

It [circles of learning] was a great way to express your feelings with people. (2013A8)

And we had them for a month, so toward the end of the month, we really got comfortable with the people there. (2014B1)

I really enjoyed the tables, having them all split up. I enjoyed sitting with new people once a month. (2015C2)

Interestingly, the most common response about the circles of learning referred not to the development of academic skills but more so to the acknowledgement of budding friendships and potential socializations that arose from the connections made in the class.

In our learning group, we also became friends, so even outside of the classroom, it was to feel their support and come to the Aboriginal centre and see 'em and talk with them too about other coursework you had. (2014B3)

I used the circle of learning as a way to become friends with some people. $\left(2015 \mathrm{C}_{3}\right)$ One student indicated that shared experiences were important:

It's nice to hear about that other people were having problems, too. $\left(2015 \mathrm{C}_{4}\right)$ 
For instance, First Nations people coming in, not feeling like they're alone, they've come from their own life, and they don't feel like they're completely different. The circle of life. You kind of get a view of everyone. (2013A4)

However, not all students had a good experience with the circles of learning. Three participants identified the lack of collaboration amongst the classmates as an inhibiting factor in the success of shared knowledge.

Frustrating. (2015C2)

I think there should be at least one leader in each group. (2013A7)

The in-class circles-I don't think it helped me in the classes. (2014B2)

Theme 1 (that circles of learning based on CRP created relationships and community) speaks to the importance of the interconnections of relationships but also underscores the salient need to address the socio-emotional needs of first year students. This type of networking supported students as they progressed through the course, providing them with a safe and respectful context where they explored camaraderie. The shared experiences of trying to create belongingness within an academic context also provided parameters upon which to build community. However, three students noted that the collaborative learning processes in the learning circles were frustrating.

Theme 2: Peer mentoring facilitated the narrative of shared experiences. In keeping with the concept of developing a supportive community of learners, peer mentors were an integral component of the course. During the interviews, students identified how the peer mentors provided social, emotional, and academic support as well as a willingness to share their own similar experiences with transition to campus life.

\section{Social and emotional support.}

And having one more person just to talk to, and pretty much discuss how you're doing. It's a good thing to have. If I didn't have that, then it would just be different. Someone to communicate with would be beneficial because I know if I didn't have anyone to talk to, I'd just feel alone and stuff, so it helped me in that way. (2013A9)

My peer mentor [name withheld], she just always knew what I was going through, so she would always give me the right advice. She was really helpful. It was always nice knowing if I ever needed something, or needed somebody, I'd have that person to call.

It's kind of like peers. Yeh, it was very impactful, they were a huge help. We had fun. [met] a couple days a week, or maybe less. It helped a lot. (2013A5)

Our talks, just knowing I had support everywhere, asked other peer mentors for help and they were super helpful. (2014B3)

\section{Academic support.}

She was always offering help to study. (2015C1) 
I really liked the peer mentoring. It was really nice going to university and not knowing anyone, and the peer mentor was always offering help for studying and coffee. (2014B4)

[Name withheld] is my peer mentor and she's really engaged in the courses. You know, she shows up to our classes. She helps a lot. It's actually been quite beneficial to have someone to talk to and we relate on a lot of subjects. So, it's been very nice. (2015C3)

They have really nice peer mentors here. They're fully dedicated to help you do the best you can do, and they just want to see you succeed at the course you're doing and pass school. (2013A7)

Yes, it's nice seeing them in there, and it makes you feel like you actually have people supporting you too. And then also when you see them in the Aboriginal Centre, they also ... they were in the class, so they know what you're working on, and they know exactly what you have to do. So then when you go to ask them, they're always there and they know exactly what you need to do. (2014B1)

Shared experiences. As indicated, respondents were particularly appreciative of the shared experiences of their mentors.

[Yeh. Just somebody who went through the course and knows what it takes to do, to pass it. And they have that leadership, and you can look up to them and ask them for help if the teacher's not available. (2015C1)

I liked them. They were helpful, you kind of have an idea of where other people have come from, their struggles. (2013A10)

She's really committed. I see her almost everyday, and no matter what she's doing, she's willing to sit down and work through everything or even just talk. Yeh, she's had an interesting, eventful life, and so she can kind of relate to almost any feeling I've had this semester. She gets it; she's been there, so ... we've just had some same experiences. (2014B4)

Despite the accolades regarding peer mentoring, some students did not find that this support was academically beneficial. However, they did recognize the social and emotional support provided.

I had my peer mentor, but it's just more of like another student in the Ab[original] Centre that you're saying hi to. Not really. I see them kind of like people to hang out with more so. $\left(2015 \mathrm{C}_{3}\right)$

I didn't really use the peer mentor too much, but I'm sure it wouldn't have been negative if I'd used it more, it's hard not knowing that many people. (2013A2)

Notwithstanding the above comments, the majority of these results emphasized the socio-emotional and academic support provided by the peer mentors. This is in keeping with recognized research that states the peer mentoring role is a valuable experience that 
charts new career objectives and lifelong personal change (Barefoot, 1993; Barefoot \& Fidler, 1996; Barefoot, Gardner, Cutright, Morris, \& Schroeder, 2005; Ender \& Newton, 2000). Furthermore, this type of mentoring is representative of an Indigenous cultural intergenerational approach to helping and teaching while creating supportive relationships (Archibald, Pidgeon, \& Hawkey, 2009; Pidgeon, Archibald \& Hawkey, 2014). This type of support is emphasized in CRP literature as a strategy in which students develop camaraderie and a work ethic as they critically and creatively explore curricula (LadsonBillings, 1994).

Theme 3: The importance of student-teacher relationship. Here are several comments that speak to the nature of the relationship between student and teacher.

I enjoyed getting to know the teacher on a more personal level, rather than her not knowing who you are. And she got to actually get to know you in some way. That's what I enjoyed. (2015C1)

It was a good environment to walk in, she knows your name, and she knows who you are. It's nice to have that, other than walking in and teachers don't know you, and so they don't really care how you do. (2013A8)

I like the ability that you actually have that personal interaction with the teacher. She knows your name and you get to talk with her. I like that. I think they chose really good teachers. (2013A3)

[The teacher is hands-on.] She'll write something on the board and in our learning groups, [and we] have to come up with ideas and go up there and write it down and interact as a group ... [she gives] opportunities to get up and express yourself. (2013A5)

[The instructor] was really nice, willing to do one-on-one and stuff like that, so I felt that was really nice. (2014B3)

An important component of CRP is building relationships (Egbo, 2009; Gay, 2000; Parker, 1998). Meaningful teacher-student relationships that build on the emotional, physical, and intellectual facets, among many others, of the learner facilitate the development of a safe, respectful context. Delpit's (2006) analysis of the juxtaposition of race, ethnicity, teaching, and learning demonstrates that teachers can positively transform the lives of their students if they dispense with prejudice, stereotypes, and cultural assumptions. Egbo (2011) argues that this and cultural literacy, are the socially and morally nonnegotiable components of progressive educational programs.

\section{Discussion}

Figures 1 and 2 demonstrate the students' perceived positive values relating to the culturally responsive introduction to university course. The inclusion of the voice of Aboriginal Access students in this study is representative of the shifting mindsets of the Canadian education system. Within this new mindset there is an increased presence of First Nation Peoples' histories, languages, cultures in provincial curricula, that along with the provision of sustained leadership and informed practice, can support emergent para- 
digms upon which the Indigenization of curricula can take place (British Columbia Ministry of Education n.d.; Canadian Council on Learning, 2009; Ragoonaden, Cherkowski, Baptiste \& Després 2009). The three emergent themes identified in the data analysis of the semi-structured interviews-circles of learning created social relationships and community; peer mentoring provided socio-emotional and academic support through shared experiences; and the importance of the student-teacher relationship-indicated that the infusion of CRP in a University 101-type course was beneficial to the students' intellectual, social, emotional, and academic development. CRP asserts the value of focusing classroom curricula on students' cultural frames of reference, recognizing that this cultural congruence can increase student success. This is in keeping with Bopp et al.,'s (2004) focus on the importance of harmonizing the four components of the Medicine Wheel, situating the self as the nexus between wisdom, illumination, trust and insight. Likewise, literature related to University 101 recognizes the importance of setting and maintaining progressive goals relating to the intellectual, social, and physical well-being of first year students (Cuseo, 2002; Tinto, 1993; 2002; Upcraft and Gardner, 1989)

As indicated, peer mentoring facilitated the narrative of shared experiences and provided socio-emotional and academic support. This highlights the fact that peer mentoring ensures that first-year students are never isolated and that their academic development can be nurtured through a supportive community. The literature on the first-year experience sees persistence (Ischler and Upcraft, 2005) plus the ability to adapt in a variety of ways academically, socially, and emotionally as key to success for the first-year student (Pascarella, Terenzini, \& Wolfle, 1986; Wilke \& Kuckuck, 1989). Peer mentoring provides the kind of supportive peer interactions that Ischler and Upcraft (2005) identify as significant in helping students persist through their first college year.

Within a culturally responsive framework, the descriptive analysis of the Likert scales found in Figures 1 and 2 indicate that most of the skills necessary for admission to firstyear courses had been developed and were being applied in other concurrent courses. For example, CRP-infused strategies such as muscle reading and note-taking were being applied in a successful manner in biology and in English. Interestingly, students noted the fact that health management had been introduced briefly during the last week of classes and expressed a strong interest in spending more time on physical well-being. A minority of students also noted a lack of engagement from some classmates in the circles of learning, indicating that a lack of collaborative skills can hinder engagement and commitment of all participants. This is in keeping with previous studies that demonstrate that collaborative practices must be structured in a way that ensures an equitable division of the required work (Johnson \& Johnson, 1974; Johnson, Johnson, \& Holubec, 1990; Ragoonaden \& Bordeleau, 2000). These are important developmental skills in all first year students' educational journey. Curricula in higher education must acknowledge this disparity and respond thoughtfully and intentionally to this salient pedagogical need.

Regarding the importance of student-teacher connection, Noddings (2003) speaks emphatically about the notion of caring for and being cared for in the teacher-student relationship.

Teaching involves two people in a special relationship.... Sometimes teachers and students just explore ... this [exploration] is not prespecified, nor need it remain 
constant, or for that matter, lead somewhere definite. The essence is in relationship (Noddings, p. 195).

Reiterating Noddings (2003), Palmer (1998) states unequivocally that good teaching comes from the integrity of the teacher, from the relation between teacher and student. In fact, echoing CRP, he discredits the presence of the universal tale and calls for an acknowledgment and a validation of the plurality of contemporary society where diverse stories can be told and heard.

Parker's (1998) work is indicative of the emergent discourse emphasizing the importance of shared narratives and shared experiences. In keeping with Ogbu's (1982) conceptualization of cultural discontinuity, students' comments do reflect the disconnect between the universal tale and students home and educational contexts, resulting in feelings of alienation and marginalization that lead to lack of confidence in social situations and academic matters.

Many educational researchers echo this sentiment and acknowledge that an important component of CRP is building relationships (Anuik, Battiste, \& George, 2010; Egbo, 2009; Gay, 2000; Ladson-Billings, 1994; Nieto, 2000; 2004). Meaningful teacher-student relationships that build on the learner's emotional, physical, and intellectual facets (among many others) facilitate the development of a safe, respectful context. Egbo (2011); Ryan, Pollock, and Antonelli, (2009); and Villegas and Lucas (2002) argue that an approach asserting the value of focusing classroom curricula and practice upon students' cultural frames of reference, along with cultural literacy, are the socially and morally nonnegotiable components of progressive educational programs.

In future iterations of the course, modifications based on these preliminary results, particularly in the area of strategic collaborative learning and increased training for peer mentors, along with on-going consultations with APS and place-based First Nations communities will be considered to better meet the needs of the first-year undergraduate students. Data collected during the interviews can provide this first step in understanding best practices relating to the integration of CRP in higher education.

\section{Limitations}

Due to the small sample interview size of this study, a very limited perspective can be proposed. However, certain notable experiences demonstrating the impact of CRP may provide direction for future research. Students did appreciate the integration of CRP via the circle of learning, the presence of Aboriginal peer mentors, and the positive relationship established with the instructor.

\section{Conclusion}

Reflecting on the culturally responsive approach used in Academic Pedagogy: An Aboriginal Perspective, the Indigenization of the curriculum supported by a robust partnership with Aboriginal Programs and Services, First Nations community members, and the presence of peer mentors, fostered the development not only of academic skills but also relationships, shared experiences, and community-building in first year students. Within a limited scope, the results of this study support the thesis presented by many scholars who recommend that traditional Indigenous philosophies of education be incorporated 
into institutional programming (Anuik \& Gillies, 2012; Battiste, 2002; Claypool \& Preston, 2011; Stang \& Vedan, 2012). Battiste (2002) writes, "Indigenous knowledge is now seen as an educational remedy that will empower Aboriginal students if applications of their Indigenous knowledge, heritage, and language are integrated into the Canadian educational system" (p. 9). Battiste (2002) recognizes that the holistic nature of Indigenous knowledge is fundamental to First Nations worldviews and must always be taken into account when considering educational policy, practice, and curricula. This viewpoint is also highlighted within the First Nations Education Steering Committee's First Peoples' Principles of Learning (FNESC, 2008): "Learning is holistic, reflexive, reflective, experiential, and relational focused on connectedness, on reciprocal relationships, and a sense of place" .

The data taken from the interviews speak to the importance of the interconnectedness of the self in relationship to society and education. This precept underscores the salient need to address not only the intellectual but also the emotional, physical, and social facets of first-year students coming into a new and often foreign academic culture. Responding to the aspirations and needs of diverse learners means valuing their collective intellectual traditions and identities. This research has the potential to serve as a framework for the development of indicators to report and monitor successful CRP in first-year learning, not only in specific populations like Aboriginal Access students but also for all first-year university students experiencing the complexity of campus life.

To conclude, we refer to Pidgeon's (2009) considerations of the future of Aboriginal higher education in the British Columbia postsecondary system. Expanding on Bowles' (2009) 20 Questions for 2020, Pidgeon's response includes Indigenizing the deliberations to include recent research to propose what institutions, governments (local, provincial, federal) and First Nation, Inuit and Métis Peoples communities can do to further Indigenous education. The 20 Questions Indigenized by Pidgeon (2009) are found in Appendix A.

I would argue that a system-wide community approach to Aboriginal post-secondary education entails an active dialogue that uses Indigenous research and evidence-based practices to inform policy and practice. Reiterating Kirkness and Barnhardt's 4Rs calls again for systemic changes across the educational system that has as its foundation and fabric respect for Indigenous cultural integrity; reciprocal relationships that are meaningful and engaging; programs and services are relevant and reciprocal to the Indigenous communities, locally and globally; and responsible participation in all aspects of peoples' lives. This dialogue and systemic transformation cannot merely be le those in the larger research universities in the province. (Pidgeon, 2009 p.11)

\section{Note}

1. In Archibald et al., (1995) \& (Pidgeon, 2008), Wholistic is spelled with a "w" on purpose to reflect the interconnections and interrelationships that are an important component of Indigenous epistemologies (see Archibald et al, 2009).

\section{Acknowledgements}

The authors acknowledge the support of Adrienne Vedan, Director, Aboriginal Programs and Services, UBC's Okanagan campus, members of the Faculty of Education's Aboriginal Education Advisory and the wisdom and guidance of the peer reviewers who provided 
seminal direction in the revision process.

\section{References}

Anuik, J., Battiste, M., \& George, P. (2010). Learning from promising programs and applications in nourishing the learning spirit. Canadian Journal of Native Education, 33(1), 63-82.

Anuik, J., \& Gillies, C. (2012). Indigenous knowledge in post-secondary educators' practices: Nourishing the learning spirit. Canadian Journal of Higher Education, 42(1), 63-79.

Archibald, Jo-ann. (1995). Locally Developed Native Studies Curriculum. In M. Battiste and J. Barman (Eds.), First Nations Education in Canada: The Circle Unfolds. Vancouver: UBC Press

Archibald, J., Pidgeon, M., \& Hawkey, C. (2009). Aboriginal transitions: Undergraduate to graduate studies. U2G Phase I Final Report. Department Faculty of Education, University of British Columbia.

Armstrong, Jeannette C. (2000). Let Us Begin With Courage. Ecoliteracy: Mapping the Terrain. Berkeley: Learning in the Real World.

Armstrong, J. (2005). Okanagan education for sustainable living: As natural as learning to walk or talk. In M. Stone \& Z. Barlow (Eds.), Ecological literacy: Educating our children for a sustainable world (pp. 80-84). San Francisco, CA: Sierra Club Books.

Ball, A. (2009). Towards a theory of generative change in culturally and linguistically complex classrooms. American Educational Research Journal, 46(1), 45-72.

Ball, A., \& Tyson, C. (Eds). (2011). Studying Diversity in Teacher Education. Lanham, MD: Rowman \& Littlefield.

Barefoot, B. O. (Ed.). (1993). Exploring the evidence: Reporting outcomes offreshman seminars (Monograph No. 11). Columbia, SC: University of South Carolina, National Resource Center for the Freshman Year Experience.

Barefoot, B. O. (2000). The first-year experience: Are we making it any better? About Campus, 4(6), 2-18.

Barefoot, B. O., Berman, D., Gardner, J. N., Henscheid, J., Hunter, M. S., \& Swing, R. (2001). Strengthening first-year seminars: A foundation for student success (Teleconference video and print resource packet). Available from the University of South Carolina, National Resource Center for The First-Year Experience and Students in Transition.

Barefoot, B., \& Fidler, P. (1996). The 1994 national survey of freshman seminar programs: Continuing innovations in the collegiate curriculum (Monograph No. 20). Columbia, SC: University of South Carolina, National Resource Center for the Freshman Year Experience and Students in Transition.

Barefoot, B.O., Gardner, J. N., Cutright, M., Morris, L. V., \& Schroeder, C. C. (Eds.). (2005). Achieving and sustaining institutional excellence for the first year of college. San Francisco, CA: Jossey-Bass,. 
Battiste, M., \& Henderson, J. (2009). Naturalizing Indigenous knowledge in Eurocentric education. Canadian Journal of Native Education, 32(1), 5-18.

Battiste, M. (2002). Indigenous knowledge and pedagogy in First Nations education: A literature review with recommendations. National Working Group on Education and the Minister of Indian Affairs. Ottawa, ON: Indian and Northern Affairs Canada.

Battiste, M. (2013). Decolonizing education: Nourishing the learning spirit. Saskatoon, SK: Purich Publishing.

Battiste, M., Bell, L., \& Findlay, L. M. (2002). Decolonizing education in Canadian universities: An interdisciplinary, international, Indigenous research project. Canadian Journal of Native Education, 26(2), 82-95.

Bopp, J., Bopp, M., Brown, L., \& Lane, P. (2004). The sacred tree. Twin Lakes, WI: Lotus Press.

Bowles, P. (2009). 20 questions for 2020: BC's research universities in a changing context. Vancouver, BC: Confederation of University Faculty Associations of BC. http:// scholar.google.ca/citations? user=oEKS5A8AAAAJ\&hl=en

British Columbia Ministry of Education. (n.d.). Aboriginal Education: BC's new curriculum. Retrieved from https://curriculum.gov.bc.ca/sites/curriculum.gov.bc.ca/ files/pdf/aboriginal_education_bc.pdf

Canadian Council on Social Development. (2012). A demographic profile of Canada Retrieved from http://www.ccsd.ca/factsheets/demographics/demographics.pdf

Canadian Council on Learning (2009). The State of Aboriginal Learning in Canada: A holistic approach Retrieved from http://www.afn.ca/uploads/files/education2/state_ of_aboriginal_learning_in_canada-final_report,_ccl,_2009.pdf

Cherubini, L. (2014). Aboriginal student engagement and achievement: Educational practices and sustainability. Vancouver, BC: UBC Press.

Claypool, T., \& Preston, J. (2011). Redefining learning and assessment practices impacting Aboriginal students: Considering Aboriginal priorities via Aboriginal and Western worldviews. Indigenous Education, 17(3), pp. 84-95. Retrieved from: http:// ineducation.ca/index.php/ineducation/article/view/74

Cohen, Bill. (2010).School Failed Coyote so Fox Made a New School: Indigenous Okanagan Knowledge Transforms Educational Pedagogy. PhD Thesis. Retrieved from https://circle.ubc.ca/handle/2429/30469

Cuseo, J. (2002). Organizing to collaborate: A taxonomy of higher education practices for promoting interdependence with in the classroom, across the campus, and beyond the college. Stillwater, OK: New Forums Press.

Cuseo, J. (2003). Comprehensive support for students during the first year of college. In G. L Kramer \& Associates (Eds.), Student academic services: An integrated approach (pp. 271-310). San Francisco CA: Jossey-Bass.

Delpit, L. (2006). Other people's children: Cultural conflict in the classroom. New York, NY: New Press. 
Egbo, B. (2005). Emergent Paradigm: Critical Realism and Transformative Research in Educational Administration. McGill Journal of Education, 4O(2), 267-284.

Egbo, B. (2009) Teaching for diversity in Canadian schools. Toronto, ON: Pearson Education Canada.

Egbo, B. (2011). What should preservice teachers know about race and diversity? Exploring a critical knowledge-base for teaching in 21st century Canadian classrooms. Journal of Contemporary Issues in Education, 6(2), 23-37.

Ender, S., \& Newton, F. (2000). Students helping students. San Francisco, CA: JosseyBass.

Ellis, D., Toft, D., \& Dawson, D. (2012). Becoming a master student (Canadian $5^{\text {th }}$ ed.) Toronto. ON: Nelson Education.

First Nations Education Steering Committee (FNESC). (2008). First peoples principles of learning. Retrieved from http://www.fnesc.ca/wordpress/wp content/ uploads/2011/03/PIPEL-6342c-FNESC-Learning-First-Peoples-poster-11x17.pdf

Gardner, J. N. (1980). University 101: A concept for improving teaching and learning. Retrieved from ERIC database. (ED192706).

Gardner, J. N. (1981). Developing faculty as facilitators and mentors. In V. A. Harren, M. N. Daniels, \& J. N. Buck (Eds.), Facilitating students' career development (pp. 6780). New Directions for Student Services, No. 14. San Francisco, CA: Jossey-Bass.

Gay, G. (2000). Culturally responsive teaching: Theory, research, and practice. New York, NY: Teachers College Press.

Gay, G. (2010). Acting on beliefs in teacher education for cultural diversity. Journal of Teacher Education, 61(1-2), 143-152.

Gay, G. (2013). Teaching to and through cultural diversity. Curriculum Inquiry, 43(1), 48-70. doi: 10.1111/curi.12002

Glaser, B. (1992). Basics of grounded theory analysis. Cambridge, UK: Cambridge University Press.

Glaser, B., \& Strauss, A.L. (1967). The discovery of grounded theory: Strategies for qualitative research. Chicago, IL: Aldine.

Grant, C., \& Gibson, M.(2011). Diversity and teacher education: A historical perspective. In Ball, A., \& Tyson, C. (2011) (Eds), Studying Diversity in Teacher Education: Lanham, MD: Rowman \& Littlefield.

Ishler, J. L., \& Upcraft, M. L. (2005). The keys to first-year student persistence. In M. L. Upcraft, J. N. Gardner, \& B. O. Barefoot (Eds.), Challenging and supporting the firstyear student (pp. 27-46). San Francisco, CA: Jossey-Bass.

Johnson, D. W., \& Johnson, R. T. (1974). Learning together and alone: Cooperation, competition, and individualization. Englewood, Cliffs, NJ: Prentice-Hall.

Johnson, D.W., Johnson, R.T., \& Holubec, E. J.(1990). Circlesoflearning: Cooperation in the classroom. Edina, MN: Interaction Book.

Kirkness, V. J., \& Barnhardt, R. (1991). First Nations and higher education: The four 
R's respect, relevance, reciprocity, responsibility. Journal of American Indian Education, $30(3), 1-15$.

Kitchenham, A., Fraser, T., Pidgeon, M., \& Ragoonaden, K. (2016). Aboriginal education enhancement agreements: Complicated conversations as pathways to success. Victoria: BC: British Columbia Ministry of Education..

Kuh, G. (2001) Assessing what really matters to student learning: Inside the national survey of student engagement. Change, 33(3), 10-17, 66.

Kuokkanen, R. (2007). Reshaping the university: Responsibility, Indigenous epistemes and the logic of the gift. Vancouver, BC: UBC Press.

Ladson-Billings, G. (1994). The dreamkeepers: Successful teachers of African American children. San Francisco, CA: Jossey-Bass.

Marker, M. (2004). The Four Rs revisited: Some reflections on First Nations and higher education. In L. Andres \& F. Finlay (Eds.), Student affairs: Experiences in and through Canadian post-secondary education (pp. 171-188). Vancouver, BC: UBC Press.

McGuigan, C. (2005). Malaspina's edge. The case for a University 101 course. Retrieved from https://www2.viu.ca/integratedplanning/documents/University101.pdf

National Resource Center for the First-Year Experience and Students in Transition. (2002). 2000 survey of first-year programming: Continuing innovations in the collegiate curriculum (Monograph No. 35). Columbia, SC: University of South Carolina, National Resource Center for The First-Year Experience and Students in Transition.

National Survey of Student Engagement. (n.d.) The NSSE report improving the college experience: National benchmarks of effective educational practice. Bloomington, IN: National Survey of Student Engagement. Retrieved from http://nsse.indiana.edu/pdf/ NSSE\%202000\%20National\%20Report.pdf

Nieto, S. (2000). Placing equity front and center: Some thoughts on transforming teacher education for a new century. Journal of Teacher Education, 51(3), 180-187.

Nieto, S. (2004) Affirming Diversity: The sociopolitical context of multicultural education (4th ed.). New York, NY: Allyn \& Bacon.

Noddings, N. (/2003). Caring: A feminine approach to ethics and moral education, (2nd ed). Berkeley, CA: University of California Press.

Ogbu J. U. (1978). Minority education and caste: The American system in crosscultural perspective. San Diego, CA: Academic Press.

Ogbu, J. U. (1982) Cultural discontinuities and schooling. Anthropology and Education Quarterly, 13(4), 290-307. Retrieved from doi.org/10.1525/aeq.1982.13.4.05x1505w

Padgett, R. D., \& Keup, J. (2011). 2009National survey offirst-year seminars: Ongoing efforts to support students in transition (Research Reports on College) Retrieved from

http://sc.edu/fye/research/research_presentations/files/2012\%20ACPA\%20 Presentation_FYS\%20Outcomes.pdf

Padgett, R. D., \& Keup, J. R. (2011). 2009 National Survey of First-Year Seminars: Ongoing efforts to support students in transition (Research Reports on College 
Transitions No. 2). Columbia, SC: University of South Carolina, National Resource Center for The First-Year Experience and Students in Transition.

Palmer, P. J. (1998). The courage to teach: Exploring the inner landscape of a teacher's life. San Francisco, CA: Jossey-Bass.

Parhar, N., \& Sensoy, Ö. (2011). Culturally relevant pedagogy redux: Teachers' conceptions of their work and its challenges. Canadian Journal of Education, 34(2), 189-218.

Pascarella, E., Terenzini, P., \& Wolfle, L. (1986). Orientation to college and freshman year persistence/withdrawal decisions. Journal of Higher Education, 57(2), 60-75.

Pidgeon, M. (2008). It takes more than good intentions: Institutional accountability and responsibility to Indigenous higher education. (Unpublished doctoral dissertation). University of British Columbia, Vancouver, BC. (https://open.library.ubc.ca/cIRcle/ collections/ubctheses/24/items/1.0066636)

Pidgeon, M. (2009). Indigenizing the 20 questions: Considering the future of Aboriginal higher education in BC's post-secondary system. A Submission for CUFA BC's 20 Questions for 2020 Project. Retrieved from http://scholar.google.ca/citations?user= oEKS5A8AAAAJ\&hl=en

Pidgeon, M., Archibald, J., \& Hawkey, C. (2014). Relationships matter: Supporting Aboriginal graduate students in British Columbia, Canada. The Canadian Journal of Higher Education, 44(1), 1-21.

Preston, J., \& Claypool, T. (2013). Motivators of educational success: Perceptions of grade 12 Aboriginal students. Canadian Journal of Education, 36(4), 257-279.

Ragoonaden, K. (2012). EDUC 104 Introduction to Academic Pedagogy: An Aboriginal Perspective. Instructor's Manual. Faculty of Education. UBC Okanagan.

Ragoonaden, K., \& Bordeleau, P. (2000) Collaborative learning and the internet. Educational Technology and Society, 3(3), 361-372.

Ragoonaden, K., Cherkowski, S., Baptiste, M., \& Després, B. (2009) Sntrusntm i7 captikwlh: Unravel the story, the Okanagan way. Alberta Journal of Educational Research, 55(3), 382-396.

Ragoonaden, K., Cherkowski, S., \& Berg, S. (2012). New directions in daily physical activity: Integral education, yoga and physical literacy. Physical and Health Education Academic Journal, 4(1), 1-16.

Ryan, J., Pollock, K., \& Antonelli, F. (2009). Teacher diversity in Canada: Leaky pipelines, bottlenecks, and glass ceilings. Canadian Journal of Education, 32(3), 591-617.

Shariff, F. (2008). The liminality of culture: Second generation South Asian Canadian identity and the potential for postcolonial texts. Journal of Teaching and Learning, 5(2), $67-80$.

Stang, S. \& Vedan, A. (2012, August). First steps for First Nations students: The library as a partner for student success. Paper presented at Empowering Library Services for Indigenous People-Indigenous Matters Special Interest Group, Helsinki, Finland.

Sharpe, A., \& Arsenault, J. (2009). Investing in Aboriginal education in Canada: 
An economic perspective. Retrieved from Canadian Policy Research Networks Research Report website at http://www.cprn.org/documents/51980_EN.pdf

Social Sciences and Humanities Research Council (SSHRC). (2016). Research Involving the First Nations, Inuit and Métis Peoples of Canada. Retrieved from http:// www.pre.ethics.gc.ca/eng/policy-politique/initiatives/tcps2-eptc2/chapter9-chapitre9/

Stuhldreier, M., \& Ford, M. (2009, October). Developing curriculum through integration of Aboriginal culture with educational theory and practice. PowerPoint presentation at the 7th UQAT Annual First Nations Symposium. Winnipeg, MB: Red River College.

Tinto, V. (1993). Leaving college: Rethinking the causes and cures of student attrition (2nd ed.). Chicago, IL: University of Chicago Press.

Tinto, V. (2002). Establishing conditions for student success. Presented at the 11th Annual conference of the European Access Network, Monash University, Pato, Italy.

Upcraft, M. L., \& Gardner, J. N. (1989). A comprehensive approach to enhancing freshman success. In M. L. Upcraft, \& J. N. Gardner (Eds.), The freshman year experience: Helping students survive and succeed in college (pp. 1-12). San Francisco, CA: JosseyBass.

Villegas, A. M., \& Lucas, T. (2002). Educating culturally responsive teachers: A coherent approach. Albany, NY: State University of New York Press.

Wilke, C., \& Kuckuck, S. (1989). A longitudinal study of the effects of a freshman seminar. Journal of the Freshman Year Experience, 1(1), 7-16.

\section{Contact Information}

C. Karen Ragoonaden, Ph.D.

Faculty of Education

The University of British Columbia Okanagan Campus

karen.ragoonaden@ubc.ca

Karen Ragoonaden's research and publications reflect her commitment to provide educational leadership in the scholarship of teaching and learning. In keeping with the emphasis on the self, society, and education, this work builds on her academic and educational leadership conceptualizing culturally responsive approaches to teaching, learning, and curriculum development and innovation.

Lyle Mueller is a former Advisor, Aboriginal Education to the Provost, and the former Director of Aboriginal Programs and Services, at University of British Columbia Okanagan Campus. At present, his focus is on broad projects and maintenance of relationships with Aboriginal communities. Mueller began his career as a teacher in Saskatchewan's Aboriginal high school programs. He started as Aboriginal Education Coordinator at Okanagan University College (OUC) in 1992, and served in Aboriginal programs at both OUC and UBC. He is the co-author of the Mathematics 104 textbook for Aboriginal Access Program students and co-developer of culturally relevant access courses for Aboriginal students. 


\section{Appendix A}

\section{Questions Indigenized by M. Pidgeon (2009)}

1. What explains BC's Aboriginal peoples' historically low participation rate? How can their participation rates be increased?

2. In considering a learning environment designed to maximize success based on Indigenous epistemology, ontology, and axiology, what support mechanisms need to be in place for faculty and students?

3. How do Aboriginal participation rates vary by region? To what extent does the availability of a university or other institution locally reduce differences? What challenges face multi-campus research universities?

$4 / 5$. What strategies are needed to improve access to and increase greater postsecondary education (PSE) participation and degree completion among Aboriginal students (including low income and/or first generation students)?

6. What should the relationships be between the research university and Aboriginal community?

7. How can institutions develop optimal policies to attract Aboriginal students, increasing accessibility and maintain adequate funding levels for research universities?

8. What funding framework would provide research universities with adequate and predictable operating grants to support Indigenous growth and development across the institution?

9. How should $\mathrm{BC}$ fund Aboriginal graduate student spaces and recruit and retain the best and brightest Aboriginal graduate students?

10. What is the role, and benefit, of further developing the link between Indigenous research and Indigenous pedagogy in BC's postsecondary system?

11. How should research universities respond to the government direction of and implicit hierarchies within Aboriginal funding at the provincial and national levels?

12. How should Indigenous-directed/funded research and the commercialization of research (particularly as it pertains to the intellectual property rights of Indigenous peoples) be managed in contemporary research universities?

13. What governance structures (including Aboriginal governance models) might universities learn from to offer high quality educational programs and advance frontiers of Indigenous knowledge?

14. What Indigenous accountability mechanisms will ensure public universities spend public monies for intended purpose and are fulfilling Aboriginal mandates without government directly or indirectly violating institutional autonomy?

15. How should Indigenous knowledge and academic freedom be protected in the contemporary university?

16. How should pursuit of knowledge for its own sake be balanced with needs of the labour market, Aboriginal nations, Aboriginal communities, and society as a whole?

17. How should universities seek to Indigenize-locally and globally?

18. How should BC's degree programs and degree granting institutions be regulated to ensure students are being offered legitimate and high quality educational programs for Aboriginal communities and their students? 